\title{
Testicular Metastasis of Prostate Cancer: A Case Report
}

\author{
Ayumu Kusaka Takuya Koie Hayato Yamamoto Itsuto Hamano \\ Takahiro Yoneyama Yasuhiro Hashimoto Chikara Ohyama \\ Yuki Tobisawa Tohru Yoneyama \\ Department of Urology, Hirosaki University Graduate School of Medicine, Hirosaki, Japan
}

\section{Key Words}

Prostate cancer · Testicular metastasis · Orchiectomy

\begin{abstract}
The incidence of secondary neoplasms of the testis during autopsies is approximately $2.5 \%$. Although most secondary testicular metastases are due to prostate cancer, only a few patients with prostate cancer have clinically manifested testicular metastasis. We report the case of a prostate cancer patient with testicular metastasis who was diagnosed after the presence of a palpable mass in the right testis. A 56-year-old Japanese male presented to our hospital with an elevated serum prostate-specific antigen (PSA) level of $137 \mathrm{ng} / \mathrm{ml}$. He was diagnosed with stage IV (T3N1M1b) prostate cancer and received androgen deprivation therapy, followed by various hormonal manipulations. His serum PSA level was undetectable for 1 year. No distant metastases were detected during imaging examinations. He received radiation therapy; however, his serum PSA level increased gradually. Four months later, he presented with right testicular swelling. Computed tomography revealed a heterogenous mass in the right testis and a right high inguinal orchiectomy was performed. Histopathological analysis showed that the right testis was infiltrated with metastatic adenocarcinoma with a Gleason score of 8 . This is a rare case of right testicular metastasis in a patient with prostate cancer. Testicular metastasis of prostate cancer can be aggressive and metastasize.
\end{abstract}

(C) 2014 S. Karger AG, Basel

\section{Introduction}

The incidence of secondary neoplasms of the testis during autopsies is approximately $2.5 \%$, including nonneoplastic deaths [1]. Most secondary testicular metastases originate from distant primary sites, of which the lung, prostate, and gastrointestinal tract are

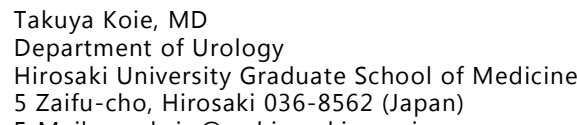


Kusaka et al.: Testicular Metastasis of Prostate Cancer: A Case Report

common [2]. Testicular metastases occur in up to $4 \%$ of all prostate cancer (PCa) cases and are often detected incidentally after orchiectomy treatment for advanced disease [3]. Generally, PCa metastases to the pelvic lymph nodes, bones, lungs, and liver occur frequently in the advanced stages; however, few of these patients have clinically manifested testicular metastasis [4]. We report the case of a patient with PCa with testicular metastasis who was diagnosed based on the presence of a palpable mass in the right testis.

\section{Case Presentation}

A 56-year-old Japanese male presented to our hospital with an elevated serum prostatespecific antigen (PSA) level of $137 \mathrm{ng} / \mathrm{ml}$. On digital examination, the prostate was palpable with hard consistency on both lobes. He underwent a transrectal ultrasound-guided systematic sextant biopsy. Histological examination revealed adenocarcinoma of the prostate with a Gleason score of 9 (fig. 1). Computed tomography (CT) showed multiple lymph node enlargements from the pelvis to the bifurcation of the left renal artery. Bone scan imaging showed multiple skeletal metastases in the left ilium and ischium.

Written informed consent was obtained from the patient for the publication of this case report and the use of the accompanying images. A copy of the written consent is available for review by the Editor-in-Chief of this journal.

The patient was diagnosed with stage IV (T3N1M1b) PCa. He received androgen deprivation therapy (ADT) for 4 years, followed by luteinizing, hormone-releasing hormone and estramustine for 1 year. His serum PSA level was undetectable for 1 year, and no lymph node enlargement and no distant or skeletal metastases were visualized using imaging examinations. He received radiation therapy to the prostate $(74 \mathrm{~Gy} / 37$ fractions). Although he underwent ADT, his serum PSA level increased gradually. He presented with a right testicular swelling 4 months later. CT revealed a heterogeneous mass of $5 \times 4 \mathrm{~cm}$ in the right testis (fig. 2). Laboratory results for $\alpha$-fetoprotein, human chorionic gonadotropin, and lactate dehydrogenase were negative, and his serum PSA level had increased to $4.94 \mathrm{ng} / \mathrm{ml}$. A right high inguinal orchiectomy was performed. Macroscopic examination of the resected testis revealed a solid yellowish-white tumor of $5 \times 4 \mathrm{~cm}$. Histopathological analysis showed that the right testis was infiltrated by metastatic adenocarcinoma with a Gleason score of 8 (fig. 3). Immunohistochemical examination revealed that tumor cells were diffusely positive for PSA and $\alpha$-methylacyl CoA racemase (P504S). The patient was diagnosed with right testicular metastasis of PCa.

The patient has been asymptomatic and disease-free with a serum PSA level that decreased to an undetectable level 1 year after surgery.

\section{Discussion}

With the exception of the infiltration of leukemia and lymphoma, secondary neoplasms of the testis are rare, with a reported incidence of $0.02-2.5 \%[1,2,5,6]$. The most common primary site of testicular metastases is the prostate (15\%), followed by the lung, melanomas, skin, colon, and kidney [7]. However, most testicular metastases of PCa were identified after the examination of large numbers of testes from patients with tumors who had undergone therapeutic orchiectomies [8, 9]. Nevertheless testicular metastases of PCa are rare. Bubendorf et al. [7] studied a cohort of 1,589 patients with PCa and reported that $35 \%$ had 
hematogenous metastases most frequently involving bone (90\%), lung (46\%), and liver $(25 \%)$; metastases in the testes were found in $0.5 \%(n=3)$.

The proposed mechanisms for the spread of $\mathrm{PCa}$ to the testis include: (i) retrograde venous extension or embolism; (ii) arterial embolism; (iii) lymphatic extension, and (iv) endocanalicular spread $[6,7]$. The involvement of the prostatic urethra in PCa increases the risk of testicular metastases [3]. In our case, retrograde venous extension might have caused testicular metastasis due to embolism after radiation therapy.

The histological features of testicular metastasis are similar to those of primary $\mathrm{PCa}$ [10]. Most patients with PCa with lymph node involvement or skeletal metastases undergo ADT for several years. In previous studies, the interval from diagnosis of PCa to testicular metastasis ranged from 2.5 to 15 years [11-13]. Therefore, the histological pattern of testicular metastasis might change to another subtype of PCa such as small cell carcinoma [3]. Tu et al. [3] reported that the pathological features of testicular metastases resembled ductal or endometrioid adenocarcinoma of the prostate and that tumors contained tall columnar cells in a papillary, cribriform, and/or solid pattern. Therefore, a ductal prostate adenocarcinoma that metastasizes to the testis might be an admixture of different tumor types arising from specific prostatic stem cells [3].

In patients with testicular metastasis of $\mathrm{PCa}$, survival after diagnosis is usually $<1$ year [14]. Lu et al. [15] found that the mean survival period after orchiectomy was 12.8 months in patients with PCa and 7.4 months in those with other forms of cancer. Nevertheless, as in the current case, the patient's serum PSA can remain undetectable, but testicular metastasis can behave aggressively and further metastasize.

\section{Disclosure Statement}

The authors declare that there are no conflicts of interest regarding the publication of this paper.

\section{References}

1 Tiltman J: Metastatic tumours in the testis. Histopathology 1979;3:31-37.

-2 Dutt N, Bates AW, Baithum SI: Secondary neoplasms of the male genital tract with different patterns of involvement in adults and children. Histopathology 2000;37:323-331.

-3 Tu SM, Reyes A, Maa A, Bhowmick D, Pisters LL, Pettaway CA, Lin S, Troncoso P, Logothetis CJ: Prostate carcinoma with testicular or penile metastases. Clinical, pathologic, and immunohistochemical features. Cancer 2002;94:2610-2617.

4 Gunlusoy B, Arslan M, Selek E, Centinel M, Ayder AR, Cicek S: A case report: prostatic carcinoma with metastasis to the testicle. Int Urol Nephrol 2004;36:63-64.

5 Blefari R, Riso 0, Pino P: Secondary tumors of testis: two rare cases and review of the literature. Urol Int 1992;48:469-470.

6 Pienkos EA, Jablokow VR: Secondary testicular tumors. Cancer 1972;30:481-485.

7 Bubendorf L, Schopfer A, Wagner U, Sauter G, Moch H, Willi N, Gasser TC, Mihatsch MJ: Metastatic patterns of prostate cancer: an autopsy study of 1,589 patients. Hum Pathol 2000;31:578-583.

8 Silverton NP: Testicular metastasis from prostatic carcinoma. Br J Urol 1976;48:498.

-9 Price EB Jr, Mostofi FK: Secondary carcinoma of the testis. Cancer 1957;10:592-595.

10 Manikandan R, Nathaniel C, Reeve N, Brough RJ: Bilateral testicular metastases from prostatic carcinoma. Int J Urol 2006;13:476-477.

11 Ublight TM, Young RH: Metastatic carcinoma to the testis: a clinicopathological analysis of 26 nonincidental cases with emphasis on deceptive features. Am J Surg Pathol 2008;32:1683-1693.

12 D’Amico A, Cavalleri S, Rahmati M, Isgro A, Porcaro AB, Malossini G: A case of testicular metastasis from carcinoma of the prostate. Int Urol Nephrol 1995;27:593-596. 


\section{Case Reports in Oncology}

\begin{tabular}{l|l}
\hline Case Rep Oncol 2014;7:643-647 \\
\hline DOI: 10.1159/000367779 & $\begin{array}{l}\text { ○ 2014 S. Karger AG, Basel } \\
\text { www.karger.com/cro }\end{array}$ \\
\hline
\end{tabular}

Kusaka et al.: Testicular Metastasis of Prostate Cancer: A Case Report

13 Blacklock R: Testicular metastasis from carcinoma of the prostate. Br J Urol 1984;56:221-222.

14 Weitzner S: Survival of patients with secondary carcinoma of prostate in the testis. Cancer 1973;32:447449.

15 Lu L, Kuo J, Lin ATL, Chang Y, Chen K, Pan C, Chang LS: Metastatic tumors involving the testes. J Urol ROC 2000;11:12-16.

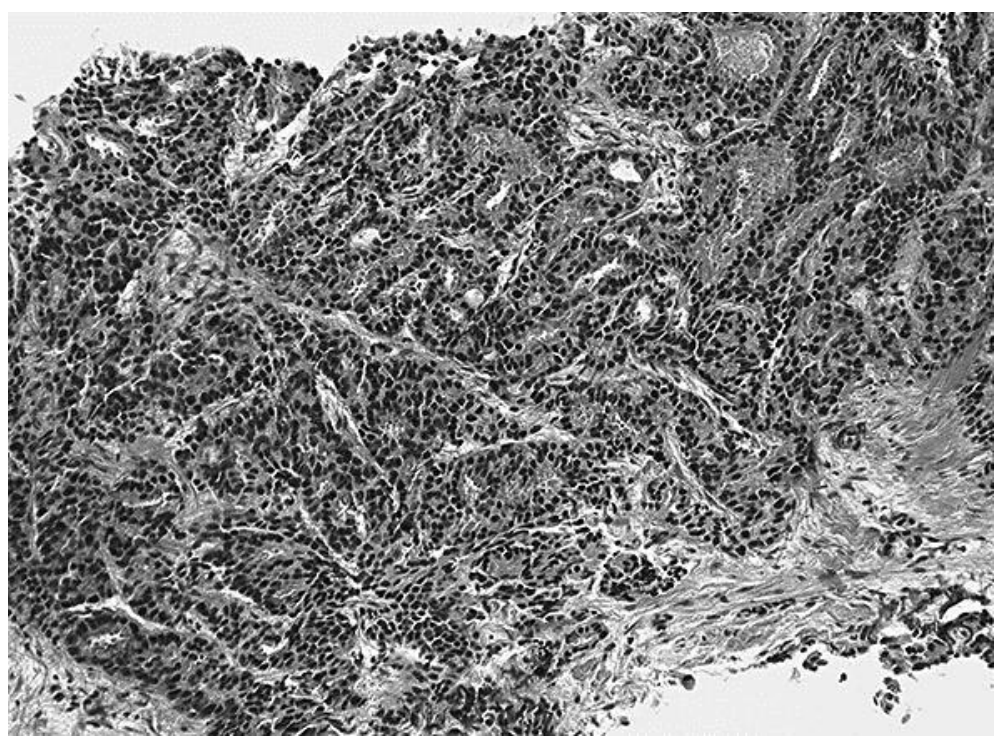

Fig. 1. HE-stained section of the primary tumor. The pathological findings indicate prostate cancer with a Gleason score of $9 . \times 100$.

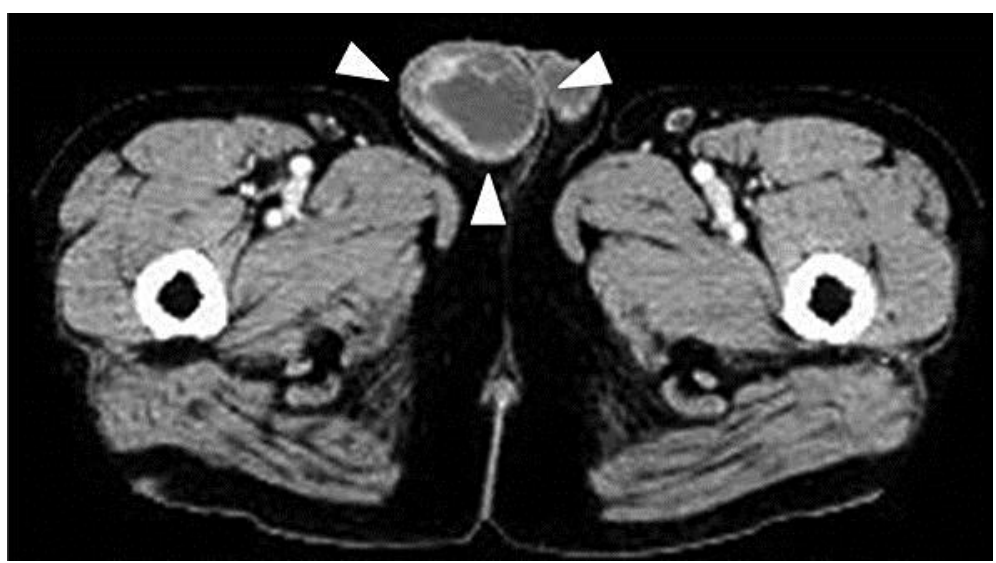

Fig. 2. Abdominal enhanced CT. Abdominal CT shows a heterogenous tumor $($ size, $5 \times 4 \mathrm{~cm})$ in the right testis (arrowheads). 


\section{Case Reports in Oncology}

\begin{tabular}{l|l}
\hline Case Rep Oncol 2014;7:643-647 \\
\hline DOI: 10.1159/000367779 & $\begin{array}{l}\text { C 2014 S. Karger AG, Basel } \\
\text { www.karger.com/cro }\end{array}$ \\
\hline
\end{tabular}

Kusaka et al.: Testicular Metastasis of Prostate Cancer: A Case Report

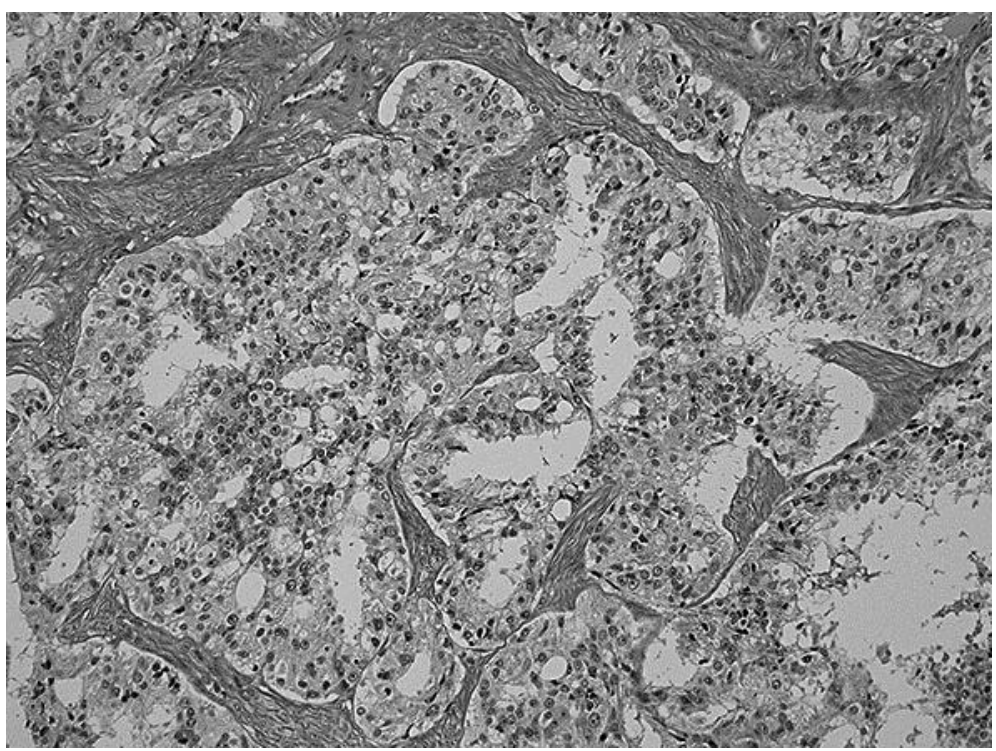

Fig. 3. HE-stained section. The pathological findings indicated prostate cancer with a Gleason score of 8. $\times 40$. 